\title{
Extended phylogenetic analysis of a new Israeli isolate of Brevicoryne brassicae virus (BrBV-IL) suggests taxonomic revision of the genus Iflavirus
}

Neta Luria, Victoria Reingold, Oded Lachman, Noa Sela and Aviv Dombrovsky

\begin{abstract}
Background: Brevicoryne brassicae virus (BrBV) is a positive-strand genomic RNA virus which is unassigned tentative member of the genus Iflavirus. BrBv was first identified and characterized in the late 90's in the cabbage aphid in the United Kingdom (UK) (J Gen Virol 88:2590-2595, 2007) and was fully sequenced, using random amplification of encapsidated RNA. No other reports have been published demonstrating detection of this virus outside the UK.

Findings: A new isolate of the cabbage aphid virus Brevicoryne brassicae virus was identified from Brevicoryne brassicae aphids growing on wild mustard plants (Sinapis arvensis) in northern Israel. The virus genome was partially assembled from purified siRNA using the Illumina MiSeq Sequencing System with limited success. Combining classical viral RNA purification and RT-PCR amplification followed by traditional Sanger sequencing enabled obtaining the complete genomic sequence. The Israeli strain of BrBV shared $95 \%$ nucleotide sequence identity with the BrBV found in the United Kingdom.
\end{abstract}

Conclusions: The detection of BrBV in Israel indicates a broader geographical distribution of the virus".

Keywords: Iflavirus, Aphid-infecting virus

\section{Background}

In the 1990s, aphid-infecting viruses were discovered and characterized; most of them contained an RNA genome. The Cripavirus genus (family Dicistroviridae) includes two aphid viruses: Rhopalosiphum padi virus (RhPV) [1-3] and Aphid lethal paralysis virus (ALPV). ALPV was first isolated from the bird cherry-oat aphid, Rhopalosiphum padi $[4,5]$, then from the oleander aphid, Aphis nerii [6], and recently from the pea aphid, Acyrthosiphon pisum [7]. In addition, two unassigned aphid viruses have been reported in previous studies: Acyrthosipon pisum virus (APV) [2] and Brevicoryne brassicae virus (BrBV) [8]. Interestingly, $\mathrm{BrBV}$ was first discovered in the United Kingdom (UK) and was fully sequenced using random amplification of encapsidated RNA. The genome organization showed that the new virus belongs to the superfamily of Picorna-like viruses [8]

\footnotetext{
* Correspondence: aviv@volcani.agri.gov.il

Department of Plant Pathology, ARO, The Volcani Center, Bet Dagan 50250, Israel
}

(c) 2016 Luria et al. Open Access This article is distributed under the terms of the Creative Commons Attribution 4.0 International License (http://creativecommons.org/licenses/by/4.0/), which permits unrestricted use, distribution, and reproduction in any medium, provided you give appropriate credit to the original author(s) and the source, provide a link to the Creative Commons license, and indicate if changes were made. The Creative Commons Public Domain Dedication waiver (http://creativecommons.org/publicdomain/zero/1.0/) applies to the data made available in this article, unless otherwise stated.
No other reports have been published demonstrating detection of this virus outside the UK. Moreover, BrBV was detected in an aphid culture infested with aphid parasitoid which showed no increase in virus replication [8]. Currently, $\mathrm{BrBV}$ is considered an unassigned virus/tentative member of the genus Iflavirus [9], which includes nine species according to the 2014 report of the International Committee on Taxonomy of Viruses (ICTV) (http:// www.ictvonline.org/virusTaxonomy.asp).

\section{Results}

From 2009 to 2012, a survey aimed at identifying aphidpathogenic viruses was conducted in Israel to find viruses that might be integrated into future biological aphid control. In the current study, BrBV-IL was found in a dense population of the cabbage aphid Brevicoryne brassicae that was highly infested by the parasitic wasp Aphidius colemani (Fig. 1a-c). The aphids were collected from wild mustard plants (Sinapis arvensis) growing in the northern 

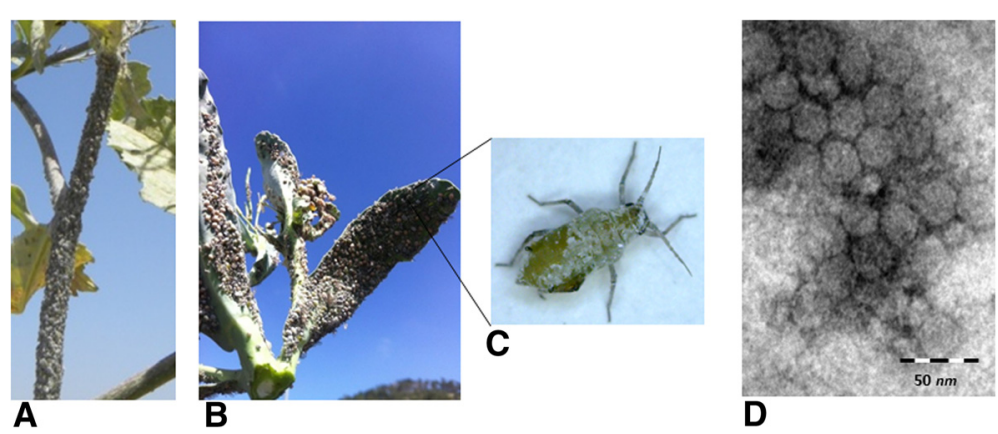

Fig. 1 Characterization of the Israeli isolate of Brevicoryne brassicae virus (BrBV-IL). a-b Natural dense population of the cabbage aphid B. brassicae harboring BrBV-Is and infested by the parasitic wasp Aphidius colemani grown on wild mustard plants (Sinapis arvensis). c Microscope enlargement of adult $B$. brassicae aphid conaining the typical white waxes powder covered most of the body surface. $\mathbf{d}$ Electron micrograph of purified particles (bar represents $50 \mathrm{~nm}$ )

coastal area of Israel and were further investigated in the current study. Later on, BrBV-IL was identified in two additional locations, Bet-Dagan and Modi'in, out of $12 \mathrm{~B}$. brassicae samples of aphid populations across the country.

Viral RNA was purified from $B$. brassicae aphids using the Viral RNA Extraction Kit (Bioneer, Daejeon, South Korea) and served as the template for a reversetranscription (RT) reaction carried out using Maxima Reverse Transcriptase (Fermentas-Thermo Fisher Scientific, Burlington, Canada) and the complementary primer R-5' -TTTAAAGAAAGAGCACTGTCCT3', followed by PCR amplification using JMR PCR mix (JMR Holdings, Kent, UK) and primer set no. 5 (Table 1), designed from the original BrBV genome (accession number NC_009530.1) [8]. Due to the high parasitoid wasp infestation of the original colony of $B$. brassicae aphids, individual adults were placed on cabbage leaves for 2 days, and then the larvae were collected and used to establish a new parasitoid-free colony of BrBV-IL-infected B. brassicae on B. oleracea plants. The established culture of $B$. brassicae aphids infected with BrBV-IL reared on brassica plants served for total RNA extraction using TRI reagent (Sigma, St. Louis, MO, USA), followed by mirVana miRNA Isolation Kit (Invitrogen, Carlsbad, CA, USA) for the enrichment of small RNA molecules. Recently, using NGS has become more and more advantageous for the discovery of new viruses and microorganisms. Moreover, the ability of whole viral assembly sequencing from small RNAs using rapid, accurate and high throughput technology allow to detect the presence of low concentration of new and cryptic viruses $[10,11]$.

The small RNA was used for the construction of a miRNA library using TruSeq Small RNA Sample Preparation Kit (Illumina, San Diego, CA, USA). The library was sequenced by the Illumina MiSeq Sequencing System (Volcani Center) and provided 217,324 reads (with 26,490 unique reads), of which only 46 reads matched the BrBV genome (accession number NC_009530.1) (Fig. 2, b).

The low genome coverage obtained with the next generation sequencing (NGS) analysis forced us to combine the traditional sequencing method based on RT-PCR amplification to retrieve the complete genome sequence.

Viral purification was carried out on $100 \mathrm{~g}$ brassica leaves carrying a dense population of BrBV-IL-infected $B$. brassicae [6]. The presence of viral particles (Fig. 1d) was verified by transmission electron microscopy (Tecnai G2, FEI-Philips, Eindhoven, The Netherlands). Viral RNA was then extracted using the Viral RNA Extraction Kit and served as a template for a RT reaction, in which oligo $\mathrm{dT}(17) \mathrm{VN}$, random hexamer and BrBV-specific primer (5'-TTTAAAGAAAGAGCACTGTCCT-3') were combined. The obtained cDNA was used as a template for the

Table 1 List of primers used for identification of the genome of the Israeli isolate of Brevicoryne brassicae virus (BrBV-IL) by RT-PCR amplification

\begin{tabular}{llll}
\hline Primer set no. & Amplicon position $(\mathrm{nt})$. & Forward primer $\left(5^{\prime} \rightarrow 3^{\prime}\right)$ & Complementary primer $\left(5^{\prime} \rightarrow 3\right)$ \\
\hline 1 & $1-1962$ & TTGAAAGATCGTGTAGGGTA & CCGGTTGTACGGAAAGGTA \\
2 & $1895-3884$ & CCGTCCATCCGATCTCTTA & CCGAATAAGTTAACCCGTGTG \\
3 & $3653-5542$ & TGAAAGCTGTAATTAACTGTGTTG & CAGGCTTACCATCAAGCCATA \\
4 & $5329-7128$ & AATGACATTCAGTGGCGTGA & AACGACAGGGCAGTCTTTG \\
5 & $7088-8920$ & ATGCACCTTGGTGTGCCTAT & GAGCTAGTTCCGACCACTCG \\
6 & $8300-10166$ & TAACTCCTCGCGACCCTAGA & TTAAAGAAAGAGCACTGTCCT \\
\hline
\end{tabular}




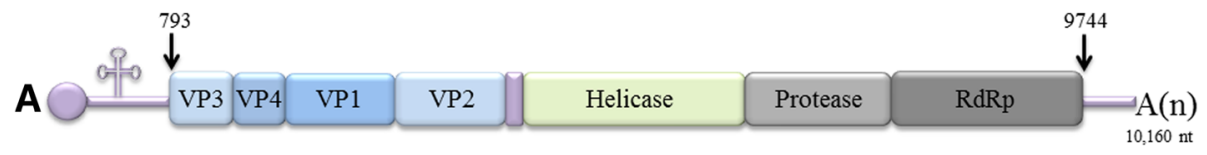

B $111,1,11-1$

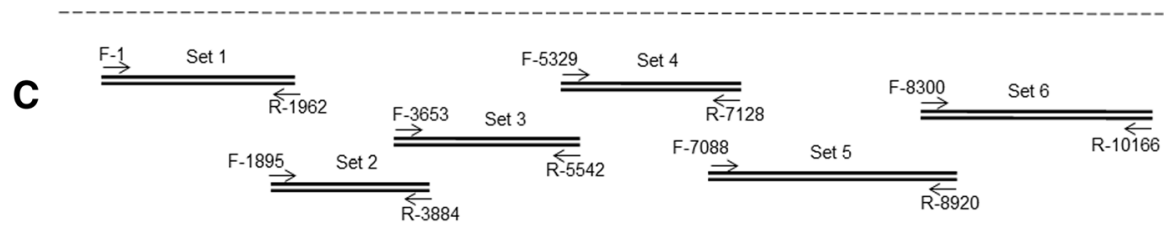

Fig. 2 Schematic representation of Brevicoryne brassicae virus (BrBV-IL) genome and illustration of the sequencing strategy. a Genomic structure of BrBV-IL genome, including the viral protein genome-linked (VPg), 5'UTR (792 nt) and 3'UTR including the 3' polyadenylated tail (419 nt including the stop codon). The long polyprotein encodes non-structural proteins, including motifs of chymotripsin-like proteinase, NTPase/helicase and RNA-dependent RNA polymerase (RdRp), and of viral structural proteins VP1-VP4. b The strategy used for BrBV-IL genome sequencing. The rectangles below the genome map represent the locations and lengths of sequences obtained by NGS analysis of siRNA. c The sequenced clones obtained by RTPCR amplification using six primer sets (Table 1) to map the entire viral genome

PCRs using six pairs of specific primers (Table 1) (Fig. 2c) which were designed mostly according to the BrBV genome from GenBank (accession number NC_009530.1) [8] and the obtained reads from the NGS data. The amplicons were cloned into pGEM-T-easy vector (Promega, Madison, WI, USA) and 2-4 clones harboring the overlapped amplicons were sequenced from both directions (HyLabs, Rehovot, Israel). The complete genome sequence of the Israeli strain of BrBV (BrBV-IL), comprised of 10,160 nt (excluding the $3^{\prime}$ polyadenylated terminal tail) (Fig. 2a) encoding a putative long open reading frame (ORF) with 2983 amino acids and two untranslated regions (UTRs) at the 5' (792 nt) and 3' (419 nt including the stop codon) ends, was submitted to GenBank under accession number KP777548.

Sequence homology of BrBV-IL determined using the Basic Local Alignment Search Tool (BLAST; http://blast.ncbi.nlm.nih.gov/Blast.cgi) revealed $95 \%$ nucleotide sequence identity and $98 \%$ deduced amino acid sequence identity to the $\mathrm{UK}$ isolate of $\mathrm{BrBV}$ (accession number NC_009530.1).

Multiple sequence alignments were analyzed using MAFFT [12] software programs. Phylogenetic trees predictions were carried out using phyml with both the long ORF amino acid sequences (Fig. 3 and Additional file 1: Figure S1-A) as well as $\mathrm{RdRp}$ amino acid sequence only (Additional file 1: Figure S1-B). First, the MAFFT program was used to align each ORF [12]. Then, a phylogenetic tree was constructed based on a maximum likelihood (ML) framework, using PhyML software [13] with 100 bootstrap replicates [14]. For the analysis $R d R p$ tree we defined the RdRp region by using the NCBI conserved domain server [15]. To further confirm our subtaxonomic groups definition analysis we also constructed a Bayesian MCMC phylogenetic tree based on the full nucleotide sequences of the viruses using MrBayes software [16] (Additional file 1: Figure S1-C). This tree also agreed on the sub-clsification determined by the previous phylogenetic trees.

Based on our NGS analysis of siRNA purified from aphids, we obtained reads matching the BrBV-IL genome. However, only preliminary knowledge of the potential infecting virus in B. brassicae allowed identification of BrBVIL, as the reads were not mapped onto significant contigs. The possibility of resequencing (assembling the reads based on the UK isolate of the BrBV genome) enabled locating the 46 reads $(0.0002 \%$ of the reads, covering $11.5 \%$ of the genome) within the genome, enabling a first determination of the viral agent with only preliminary information on nucleotide sequence. The complete genome sequence of BrBV-IL was obtained by traditional RT-PCR amplification followed by nucleotide sequencing (Fig. 2c). Although the taxonomic affiliation of $\mathrm{BrBV}$ is unclear, this study is the second report on this virus, and as such provides evidence for its global spread in B. brassicae populations.

Based on a rooted phylogenetic tree analysis of the long ORF encoding the polyprotein of the viruses belonging to the Iflavirus genus, the two unassigned $\mathrm{BrBV}$ isolates and an outgroup-Acute bee paralysis virus (NC_002548) in the family Dicistroviridae, genus Aparavirus (Fig. 3), it is suggested that the Iflavirus genus be divided into four tentative clusters: type I containing the type member Infectious flacherie virus (IFV), type II and type III (Fig. 3). As shown in Fig. 3, the two BrBV isolates are located in the type II 


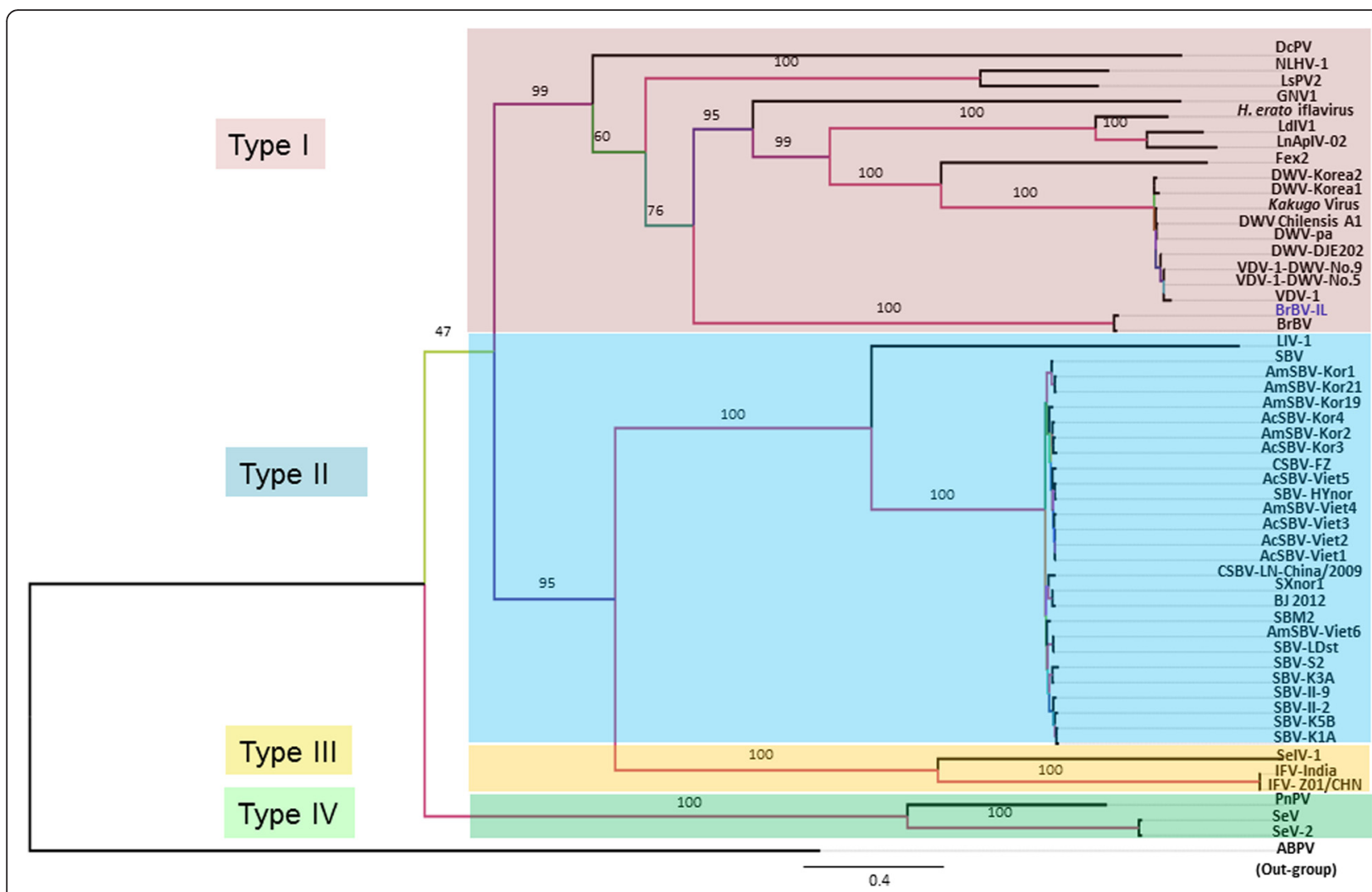

Fig. 3 Phylogenetic analysis of Brevicoryne brassicae virus (BrBV). Rooted phylogenetic tree based on the deduced amino acid sequences of the polyproteins of some members of the genus Iflavirus. Bootstrap values of 100 replicates are indicated. For visualization we used FigTree sofrtware [17] Viral sequences (with abbreviations and NCBI/GenBank accession numbers): Heliconius erato iflavirus (H.erato iflavirus; KJ679438), Spodoptera exigua iflavirus 2 isolate Korean (SeV; JN870848), Deformed wing virus isolate Chilensis A1 (DWV Chilensis A1; JQ413340), Lymantria dispar iflavirus 1 isolate Ames (LdiV1; KJ629170), Antheraea pernyi iflavirus isolate LnAplV-02 (LnApIV-02; KF751885), Perina nuda picorna-like virus (PnPV; AF323747), Sacbrood virus strain AcSBV-Kor4 (AcSBV-Kor4; KP296803), Sacbrood virus strain AcSBV-Kor3 (AcSBV-Kor3; KP296802), Sacbrood virus strain AmSBVKor2 (AmSBV-Kor2; KP296801), Sacbrood virus strain AmSBV-Kor1 (AmSBV-Kor1; KP296800), Sacbrood virus isolate AmSBV-Viet6 (AmSBV-Viet6; KM884995), Sacbrood virus isolate AcSBV-Viet5 (AcSBV-Viet5; KM884994), Sacbrood virus isolate AmSBV-Viet4 (AmSBV-Viet4; KM884993), Sacbrood virus isolate AcSBV-Viet3 (AcSBV-Viet3; KM884992), Sacbrood virus isolate AcSBV-Viet2 (AcSBV-Viet2; KM884991), Sacbrood virus isolate AcSBV-Viet1 (AcSBV-Viet1; KM884990), Sacbrood virus isolate CSBV-FZ (CSBV-FZ; KM495267), Spodoptera exigua iflavirus 2 (SeV-2; KJ186788), Sacbrood virus strain SBM2 (SBM2; KC007374), Lygus lineolaris virus 1 isolate LIV-1 (LIV-1; JF720348), Sacbrood virus strain AmSBV-Kor19 (AmSBV-Kor19; JQ390592), Sacbrood virus strain AmSBV-Kor21 (AmSBV-Kor21; JQ390591), Varroa destructor virus 1 (VDV-1; AY251269), Infectious flacherie virus strain IFV-India (IFV-India; HM569717), Nilaparvata lugens honeydew virus-1 (NLHV-1;AB766259), Brevicoryne brassicae picorna-like virus isolate IL (BrBV-IL; KP777548), Sacbrood virus CSBV-LN/China/2009 (CSBV-LN/China/2009; HM237361), Dinocampus coccinellae paralysis virus strain Quebec2013 (DcPV;KF843822), Deformed wing virus isolate Varroa-infested-colony-DJE202 (DWV- DJE202; KJ437447), Sacbrood virus isolate SXnor1 (SXnor1; KJ000692), Sacbrood virus strain BJ 2012 (BJ 2012; KF960044), Deformed wing virus strain Korea-2 (DWV-Korea2; JX878305), Deformed wing virus strain Korea-1 (DWV-Korea1; JX878304), Formica exsecta virus 2 isolate Fex2 (Fex2; KF500002), Sacbrood virus strain II-9 (SBV-II-9; JX270800), Sacbrood virus strain S2 (SBV-S2; JX270799), Sacbrood virus strain K3A (SBV-K3A; JX270798), Sacbrood virus strain K5B (SBV-K5B; JX270797), Sacbrood virus strain K1A (SBV-K1A; JX270796), Sacbrood virus strain II-2 (SBV-II-2; JX270795), Deformed wing virus isolate VDV-1-DWV-No-9 (VDV-1-DWV-No-9; HM067438), Deformed wing virus isolate VDV-1-DWV-No-5 (VDV-1DWV-No-5; HM067437), Deformed wing virus isolate PA (DWV-pa; AY292384), Infectious flacherie virus strain ZheJiang01/CHN (IFV-Z01/CHN; EU868609), Brevicoryne brassicae picorna-like virus (BrBV; EF517277), Sacbrood virus (SBV; AF092924), Kakugo virus (Kakugo virus; AB070959), Spodoptera exigua Iflavirus-1 (SelV-1; JN091707), Laodelphax striatellus picorna-like virus 2 isolate LsPV2 (LsPV2; KM272628), Graminella nigrifrons virus 1 isolate Ohio (GNV1; KP866792), Sacbrood virus strain HYnor (SBV-HYnor; KJ959614) and Sacbrood virus strain LDst (SBV-LDst; KJ959613). Acute bee paralysis virus (ABPV; NC_002548) served as outgroup

area of the phylogenetic tree, clustering together on a separate branch.

Future discovery of new members of the family Iflaviridae and further studies should shed additional light on the taxonomic affiliation among the genera. In addition, pathogenicity experiments aimed at testing the infectivity potential of BrBV-IL on different aphid species could potentially lead to future application as a biopesticide.

\section{Availability of supporting data}

BrBV-IL genome sequence was submitted to genbank under accession number KP777548. 


\section{Additional file}

Additional file 1: Figure S1. Four sub-taxomonic groups were classified according to three different trees constructed with different sequences and methodologies. (DOCX $421 \mathrm{~kb}$ )

\section{Abbreviations}

BrBv: Brevicoryne brassicae virus; BrBV-IL: Israeli isolate of Brevicoryne brassicae virus; PCR: polymerase chain reaction; NGS: next generation sequencing: sRNA: small RNA; ORF: open reading frame.

\section{Competing interests}

The authors declare that they have no competing interests.

\section{Authors' contributions}

$N L, V R$ and $O L$ did all experimental work. NS did the bioinformatics work. AD supervised and conceived the experiments. NL, VR, OL, NS and AD wrote the paper. All authors read and approved the final manuscript.

\section{Acknowledgements}

This work was supported by the Chief Scientist, Israel Ministry of Agriculture, project number 132-1456. Contribution number 550/15 from the Agricultural Research Organization, The Volcani Center, Bet Dagan, Israel.

Received: 8 November 2015 Accepted: 9 March 2016

\section{Published online: 22 March 2016}

\section{References}

1. Gildow FE, Darcy CJ. Cytopathology and Experimental Host Range of Rhopalosiphum-Padi Virus, a Small Isometric Rna Virus Infecting Cereal Grain Aphids. J Invertebr Pathol. 1990;55(2):245-57.

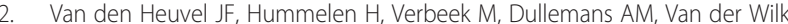
F. Characteristics of acyrthosiphon pisum virus, a newly identified virus infecting the pea aphid. J Invertebr Pathol. 1997;70(3):169-76.

3. van der Wilk F, Dullemans AM, Verbeek M, Van den Heuvel JFJM. Nucleotide Sequence and Genomic Organization of Acyrthosiphon Pisum Virus. Virology. 1997;238(2):353-62.

4. Williamson C, Rybicki E, Kasdorf G, Von Wechmar M. Characterization of a new picorna-like virus isolated from aphids. J Gen Virol. 1988;69:787-95.

5. Van Munster M, Dullemans A, Verbeek M, Van Den Heuvel J, Clerivet A, Van Der Wilk F. Sequence analysis and genomic organization of Aphid lethal paralysis virus: a new member of the family Dicistroviridae. J Gen Virol. 2002;83(12):3131-8.

6. Dombrovsky A, Luria N. The Nerium oleander aphid Aphis nerii is tolerant to a local isolate of Aphid lethal paralysis virus (ALPV). Virus Genes. 2013; 46(2):354-61.

7. Liu S, Vijayendran D, Carrillo-Tripp J, Miller WA, Bonning BC. Analysis of new aphid lethal paralysis virus (ALPV) isolates suggests evolution of two ALPV species. J Gen Virol. 2014;95(Pt 12):2809-19.

8. Ryabov EV. A novel virus isolated from the aphid Brevicoryne brassicae with similarity to Hymenoptera picorna-like viruses. J Gen Virol. 2007;88(9):2590-5.

9. King $A M Q$, Adams MJ, Carstens EB, Lefkowitz EJ. Ninth Report of the International Committee on Taxonomy of Viruses. San Diego: Elsevier; 2012.

10. Liu S, Vijayendran D, Bonning BC. Next generation sequencing technologies for insect virus discovery. Viruses. 2011;3(10):1849-69.

11. Vijayendran D, Airs PM, Dolezal K, Bonning BC. Arthropod viruses and small RNAs. J Invertebr Pathol. 2013;114(2):186-95.

12. Katoh K, Kuma K-I, Toh H, Miyata T. MAFFT version 5: improvement in accuracy of multiple sequence alignment. Nucleic Acids Res. 2005:33(2):511-8.

13. Guindon S, Dufayard J-F, Lefort V, Anisimova M, Hordijk W, Gascuel O. New algorithms and methods to estimate maximum-likelihood phylogenies: assessing the performance of PhyML 3.0. Syst Biol. 2010;59(3):307-21.

14. Guindon S, Gascuel O. A simple, fast, and accurate algorithm to estimate large phylogenies by maximum likelihood. Syst Biol. 2003;52(5):696-704

15. Marchler-Bauer A, Derbyshire MK, Gonzales NR, Lu S, Chitsaz F, Geer LY, Geer RC, He J, Gwadz M, Hurwitz DI, et al. CDD: NCBI's conserved domain database. Nucleic Acids Res. 2015;43(D1):D222-6.

16. Huelsenbeck JP, Ronquist F. MRBAYES: Bayesian inference of phylogenetic trees. Bioinformatics. 2001;17(8):754-5.

17. Rambaut A: FigTree v1. 3.1: Tree figure drawing tool. Website: http://tree.bio. ed.ac.uk/software/figtree 2009.

\section{Submit your next manuscript to BioMed Central and we will help you at every step:}

- We accept pre-submission inquiries

- Our selector tool helps you to find the most relevant journal

- We provide round the clock customer support

- Convenient online submission

- Thorough peer review

- Inclusion in PubMed and all major indexing services

- Maximum visibility for your research

Submit your manuscript at www.biomedcentral.com/submit 